\title{
Effects of Addition of Sodium Lauryl Sulfate on Frozen-thawed Canine Spermatozoa
}

\author{
Tatsuya HORI ${ }^{1)}$, Hanae KASEKI ${ }^{1)}$, Youko FUKUHARA ${ }^{1)}$, Hiromichi OBA ${ }^{1)}$, Tatsuji MIZUTANI ${ }^{1)}$, \\ Eiichi KAWAKAMI ${ }^{1)}$ and Toshihiko TSUTSUI ${ }^{1)}$ \\ ${ }^{1)}$ Department of Reproduction,Nippon Veterinary and Life Science University, 7-1 Kyonan-cho, 1 chome, Musashino-shi, Tokyo 180-8602, \\ Japan
}

(Received 29 September 2005/Accepted 8 June 2006)

ABSTRACT. The addition of Orvus ES paste (OEP) to extender may be essential for preparing frozen dog semen. The major ingredient of OEP is sodium lauryl sulfate (SLS). In this study, we compared the effect of SLS on frozen dog semen with that of OEP. There were no significant differences between the $2-\mathrm{mg} / \mathrm{m} l$ SLS group and OEP group concerning sperm motility, viability and the percentage of viable sperm with intact acrosomes after freeze-thawing. These results suggest that the effectiveness of frozen dog semen extender containing $2 \mathrm{mg} / \mathrm{m} l$ of SLS is similar effective to that demonstrated for OEP.

KEY WORDS: canine, frozen semen, sodium lauryl sulfate.

J. Vet. Med. Sci. 68(10): 1125-1128, 2006

Dog sperm is less freeze-tolerable than the sperm of other animals [5]. We previously reported that a freezing extender of canine semen, $20 \%(\mathrm{v} / \mathrm{v})$ egg yolk tris-fructose citrate solution (EYT-FC) containing $0.75 \%$ Orvus ES paste (OEP) (Equex STM paste, Nova Chemical Sales, Scituate, MA, U.S.A.), a synthetic surfactant that is used in boars [6, 14], increased sperm motility after thawing in comparison to extender without OEP addition and that sperm motility was maintained for a long period of time [17]. A high conception rate was achieved after artificial intrauterine insemination with the thawed semen [19]. In addition, we found that the sperm acrosome cap after thawing was protected by the addition of OEP to the extender [18]. Thus, OEP may be essential for preparing frozen canine semen $[9,11-13,15]$.

The major ingredient of OEP is sodium lauryl (dodecyl) sulfate (SLS), but its concentration is unclear. Kato et al. [7] employed a freezing extender of boar semen containing SLS $(1.2$ to $1.6 \mathrm{mg} / \mathrm{m} l)$ instead of OEP and reported that the percentage of normal acrosomes and progressively motile sperm after thawing with the addition of SLS were similar to that of OEP. Furthermore, several studies have reported the usefulness of frozen semen extender containing SLS in many animals (the cow [3], mouse [4], goat [1, 2], and boar [7]). In dogs, Peña et al. [10] added SLS to freezing extender for canine semen and reported that sperm viability after thawing was higher than for extender without SLS addition and that sperm survival was prolonged. However, no study has compared the usefulness of SLS and OEP added to freezing extender for canine semen.

In this study, we investigated the optimal concentration of SLS supplemented to EYT-FC in a freezing method we previously reported [17] and compared the effect of SLS on the post-thaw survival of canine sperm with that of OEP.

The male dogs used in this study, 6 beagles from 1 to 6 years of age, had normal semen quality and fertility. Two dogs were kept in each $160 \times 75 \times 65 \mathrm{~cm}$ cage. Commercial dog food (Hill's Canine Maintenance, Hill's-Colgate Ltd., Tokyo, Japan) was given once daily and drinking water was given three times daily. This study was conducted in conformity with the animal study guidelines of Nippon Veterinary and Life Science University.

The semen samples, collected by digital manipulation, were divided into three fractions. We used the 2nd (spermrich) fraction. Semen volume, the number of spermatozoa, and sperm motility, viability, and abnormality were determined by methods described previously [17]. The sperm concentration was determined by hematocytometer counts. Sperm motility was assessed as the percentage of actively motile sperm with a semen quality examination plate and a warm-plate. The percentage of viable sperm and morphologically abnormal sperm were assessed by eosin-nigrosin staining. In order to examine SLS at various concentrations under the same conditions, semen from two to three dogs was mixed and used in one experiment.

In Experiment 1, an optimal addition concentration of SLS was determined. The effect of SLS addition to EYTFC was examined at final concentrations of $0,1,2,3$, and 4 $\mathrm{mg} / \mathrm{m} l$ (SLS group), and the addition of $0.75 \%$ OEP was examined as the control (OEP group). All six groups were examined with the same semen.

After examination of semen quality, the semen was frozen according to the method previously reported [17]. The mixed semen was centrifuged at $600 \times \mathrm{g}$ for $5 \mathrm{~min}$ to remove the seminal plasma and was subjected to first dilution with EYT-FC. The semen was then divided into 6 fractions. Using second extender supplemented with 14\% glycerol and at each concentration of SLS or OEP, the semen was diluted by the drip method with stirring for approximately $10 \mathrm{~min}$. Both primary and secondary dilutions were performed at room temperature $\left(20^{\circ} \mathrm{C}\right)$. The semen was then subjected to first refrigeration at $4^{\circ} \mathrm{C}$ for $1 \mathrm{hr}$ using a program freezer (UH-JF, Chino Corporation, Japan). The semen was loaded into $0.5 \mathrm{~m} l$ plastic straws $\left(0.5 \times 10^{8}\right.$ spermatozoa) and frozen using a conventional freezer (simpletype quick LNG freezer, Fujihira Industry, Co., Ltd., Japan). More than 1 week later, the samples were thawed in warm 
water at $37^{\circ} \mathrm{C}$ for $45 \mathrm{sec}$, and semen quality was evaluated. After sperm motility, viability, and abnormality of the thawed semen were evaluated, time-course changes in sperm motility and viability were examined at $20^{\circ} \mathrm{C}$ after 1 , 2, 4, and $6 \mathrm{hr}$. This experiment was repeated six times.

In Experiment 2, the presence or absence of acrosome caps in viable sperm was observed using the triple-stain technique [16] for the SLS and OEP groups $6 \mathrm{hr}$ after thawing. This experiment was repeated six times.

The sperm parameters, including sperm motility, viability, and abnormality and the percentage of viable spermatozoa with an intact acrosome cap, were analyzed among the groups by one-way ANOVA and Duncan's multiple-range test. A probability value below 5\% was considered significant.

Experiment 1: Establishment of the optimal concentration of SLS

The time-course changes in sperm motility after thawing are shown in Fig.1. Sperm motility immediately after thawing was highest in the OEP group $[24.2 \pm 3.8 \%$ (SD)]. Among the SLS groups, sperm motility was highest in the 2$\mathrm{mg} / \mathrm{m} l \mathrm{SLS}$ group $(21.7 \pm 9.8 \%)$. However, there were no significant differences between the $2-\mathrm{mg} / \mathrm{ml}$ and 0 to $3 \mathrm{mg} /$ $\mathrm{m} l$ SLS groups. In the $4-\mathrm{mg} / \mathrm{m} l$ SLS group, motility was lowest $(10.0 \pm 7.7 \%)$ with significant differences in comparison with all other groups $(\mathrm{p}<0.01$ and $\mathrm{p}<0.05)$. At 1 and 2 $\mathrm{hr}$ after thawing, sperm motility in the OEP group was significantly higher than that in the 4-mg/ml SLS group; however, there were no significant differences between the OEP and 0 to $3-\mathrm{mg} / \mathrm{m} l$ SLS groups. There were no significant differences 4 or $6 \mathrm{hr}$ after thawing among all the groups.

The time-course changes in sperm viability after thawing for each treated group are shown in Fig. 2. Sperm viability immediately after thawing was highest in the OEP group $(52.5 \pm 13.0 \%)$. Among the SLS groups, sperm viability was highest in the $2-\mathrm{mg} / \mathrm{m} l$ SLS group $(49.4 \pm 12.1 \%)$ and was lowest in the $4-\mathrm{mg} / \mathrm{m} l$ SLS group $(38.8 \pm 11.1 \%)$. There were no significant differences in sperm viability immediately after thawing among the groups including the OEP group. However, 1 and $6 \mathrm{hr}$ after thawing, sperm viability in the OEP group was significantly higher than that in all SLS groups $(\mathrm{p}<0.01$ and $\mathrm{p}<0.05)$. In the $4-\mathrm{mg} / \mathrm{m} l \mathrm{SLS}$ group, sperm viability was significantly lower than in the 2 $\mathrm{mg} / \mathrm{ml}$ SLS group $6 \mathrm{hr}$ after thawing $(\mathrm{p}<0.05)$.

Sperm abnormalities before freezing and immediately after thawing for each treated group are shown in Fig. 3. In all groups, sperm abnormality after thawing was higher than before freezing; there was a significant difference in the 0 and $1-\mathrm{mg} / \mathrm{m} l \mathrm{SLS}$ groups between before freezing and after thawing $(\mathrm{p}<0.05)$. However, there were no significant differences in sperm abnormality after thawing among all the groups.

Experiment 2: Examination of the sperm acrosome cap

Based on the results of Experiment 1, we examined in Experiment 2 the presence or absence of the sperm acrosome cap in the $2-\mathrm{mg} / \mathrm{m} l$ SLS and OEP groups. The percentages of viable sperm with an intact acrosome cap before freezing, immediately after thawing, and $6 \mathrm{hr}$ after thawing are shown in Fig. 4. The percentages of viable sperm with an intact acrosome cap were 79.7 to $94.8 \%$ (mean: $89.3 \pm 5.5 \%$ ) before freezing. Immediately after thawing, the percentages of viable sperm with an intact acrosome cap were $39.9 \pm 12.6 \%$ and $40.4 \pm 9.4 \%$ in the 2 $\mathrm{mg} / \mathrm{ml} \mathrm{SLS}$ and OEP groups, respectively; the percentages were significantly lower than before freezing $(\mathrm{p}<0.01)$. However, there was no marked difference between the 2

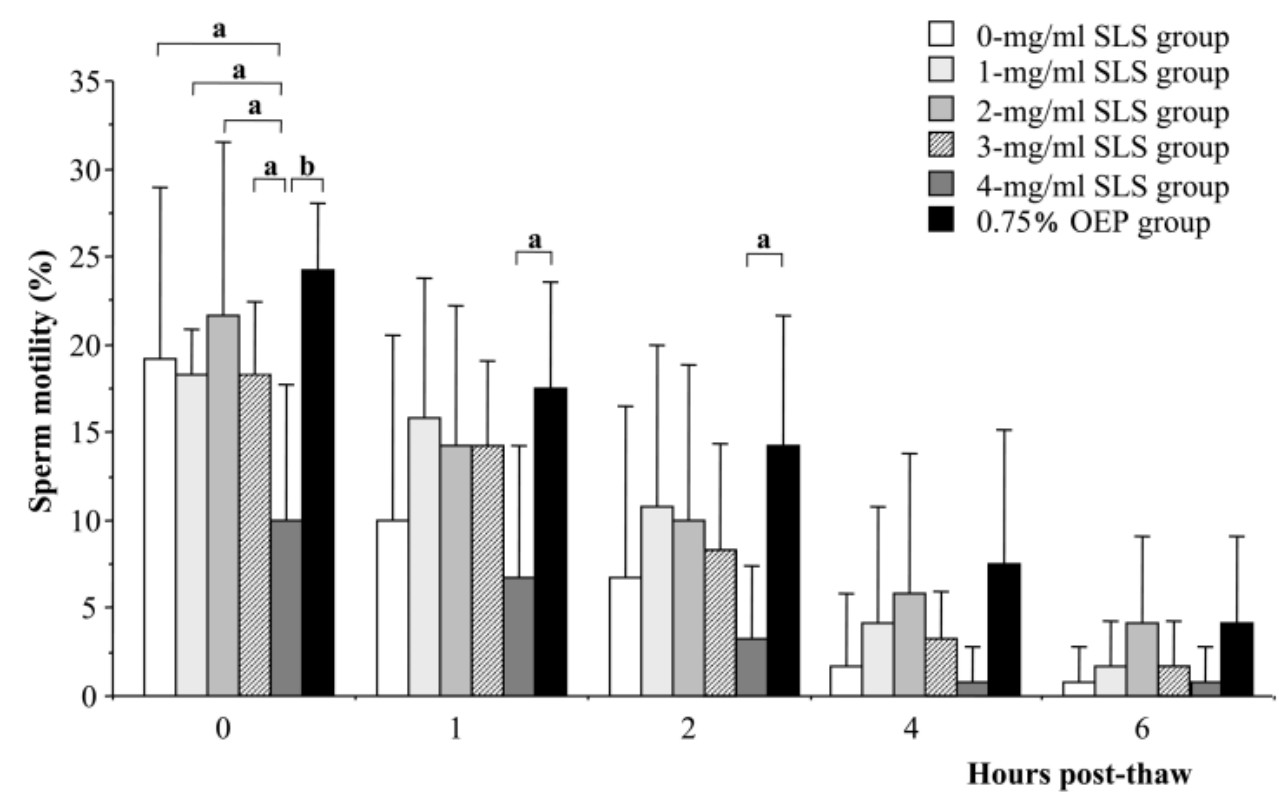

Fig. 1. Time-course changes in post-thaw canine sperm motility for each treated group (mean $\pm \mathrm{SD}, \mathrm{n}=6$ ). Significantly different between the two groups at $\mathrm{p}<0.05$ (a) and $\mathrm{p}<0.01$ (b). 


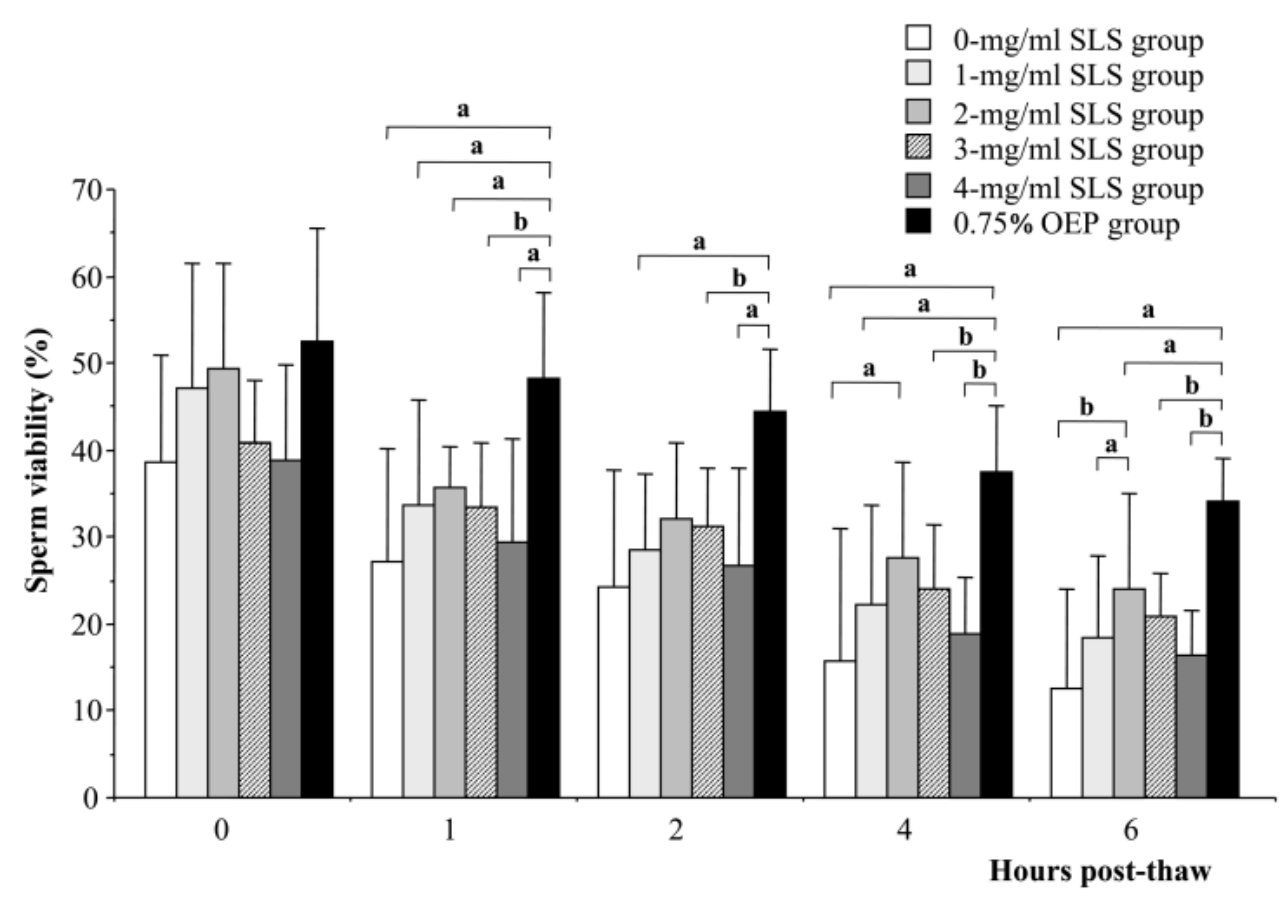

Fig. 2. Time-course changes in post-thaw canine sperm viability for each treated group (mean $\pm \mathrm{SD}, \mathrm{n}=6$ ). Significantly different between the two groups at $\mathrm{p}<0.05$ (a) and $\mathrm{p}<0.01$ (b).

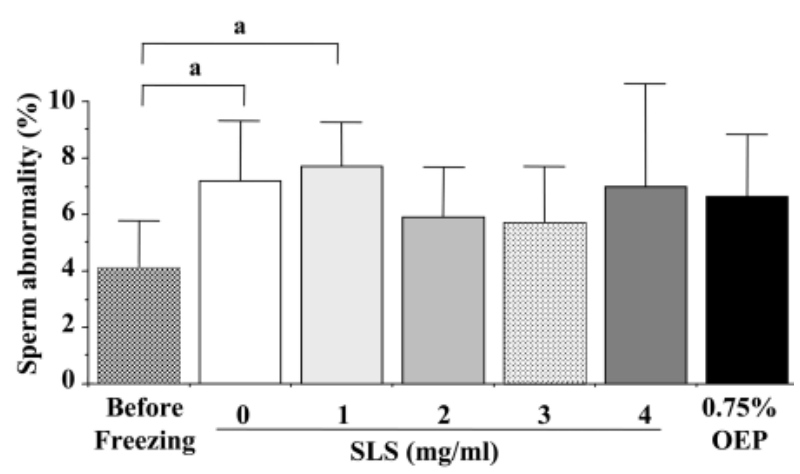

Fig. 3. Sperm abnormality before freezing and immediately after thawing for each treated group (mean $\pm S D, n=6$ ). Significantly different between the two groups at $\mathrm{p}<0.05$ (a).

groups. Furthermore, the percentages of viable sperm with an acrosome cap $6 \mathrm{hr}$ after thawing were markedly lower than the values immediately after thawing $(\mathrm{p}<0.01)$. However, there was no marked difference between the $2-\mathrm{mg} / \mathrm{ml}$ SLS and OEP groups.

As the SLS concentration in OEP is unclear, the optimal concentration for frozen canine semen remains to be clarified. However, because both OEP and SLS are spermatocidal agents [8], it was necessary to investigate an appropriate concentration for canine frozen semen. In our study, sperm motility and viability were highest in the $2-\mathrm{mg} /$ $\mathrm{m} l$ SLS group. The optimal concentrations of SLS are 1.2 to $1.6 \mathrm{mg} / \mathrm{ml}$ in boars [7], $0.035 \%$ in mice [4], and $0.035 \%$ in

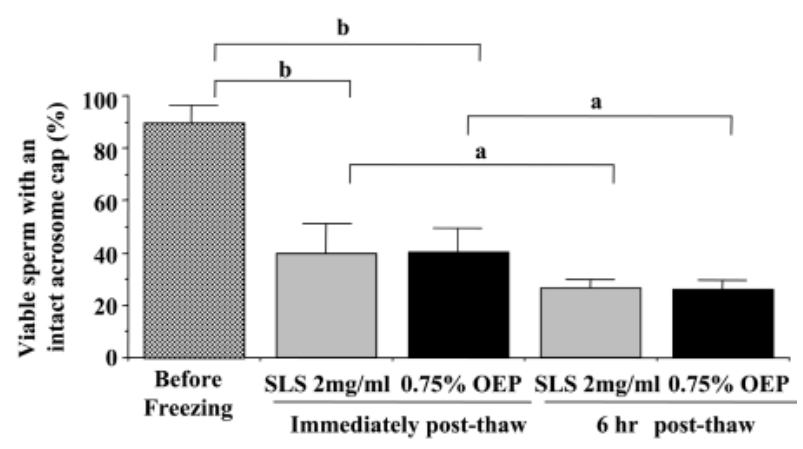

Fig. 4. The percentages of viable sperm with an intact acrosome cap before freezing, immediately after thawing, and $6 \mathrm{hr}$ after thawing (mean $\pm S D, n=6$ ). Significantly different between the two groups at $\mathrm{p}<0.05$ (a) and $\mathrm{p}<0.01$ (b).

goats $[1,2]$; the values differ among species. Peña et al. $[10]$ have reported that the longevity and viability of thawed dog semen increased with the addition of $0.25 \%$ SLS to the extender, which is similar to the results of this study.

When the results were compared between the $2-\mathrm{mg} / \mathrm{ml}$ SLS and $0.75 \%$ OEP groups, there was a significant difference in sperm viability 1,2 , and $6 \mathrm{hr}$ after thawing. However, there was no significant difference in sperm motility between the two groups from immediately after thawing until $6 \mathrm{hr}$. Therefore, dog semen frozen with the addition of SLS to the extender may improve spermatozoal longevity in a similar manner as OEP. However, in the present study, sperm motility and viability were higher in the OEP group. 
Although components other than SLS are considered to have a beneficial effect, this remains to be elucidated because the ingredients of OEP are unclear.

In dog semen frozen without the addition of OEP, sperm motility and viability immediately after thawing were similar to the values in the OEP-treated group [17]. However, because the survival of thawed dog semen without OEP was shorter than that of thawed semen with OEP, no conceptions have been obrained despite an increase in the number of sperm for intrauterine insemination [19]. This was possibly because the sperm acrosome cap was protected in the OEPtreated group [18]. Thus, increasing the rate of protected sperm may be more important than sperm motility and viability immediately after thawing [10]. Therefore, in Experiment 2, we compared the rate at which the sperm acrosome cap was maintained after thawing between the $2-\mathrm{mg} / \mathrm{m} l \mathrm{SLS}$ and $0.75 \%$ OEP groups. There was no marked difference between the two groups. This proves that the sperm acrosome cap is maintained in the presence of SLS, preventing freezing treatment-related damage.

In conclusion, frozen dog semen extender containing 2 $\mathrm{mg} / \mathrm{m} l \mathrm{SLS}$ was effective. Sperm motility and the percentage of intact acrosomes immediately after thawing were similar to the values when frozen dog semen extender containing $0.75 \%$ OEP was employed. Therefore, in the future, it will be necessary to determine whether a conception rate similar to that obtained using frozen semen containing OEP can be obtained by the addition of $2 \mathrm{mg} / \mathrm{m} l \mathrm{SLS}$.

\section{REFERENCES}

1. Aboagla, E. M. and Terada, T. 2004. Theriogenology 62: 809818.
2. Aboagla, E. M. and Terada, T. 2004. Theriogenology 62: $1160-1172$.

3. Ahmad, K. and Foote, R. H. 1986. J.Dairy Sci. 69: 535-541.

4. Dewit, M., Marley, W. S. and Graham, J. K . 2000. Cryobiology 40: $36-45$.

5. England, G. C. 1993. J. Reprod. Fertil. (Suppl.) 47: 243-255.

6. Graham, E. F., Rajamannan, A. H. J., Schmehl, M. H. K., MakiLaurila, M. and Bower, R. E. 1971. AI Digest 19: 12.

7. Kato, S., Miyano, T., Nanjo, I., Yasui, T. and Kanda, S. 1990. Jpn. J. Anim. Reprod. 36: 26-30.

8. Mann, T. 1964. pp. 379-396. In: The Biochemistry of Semen and the Male Reproductive Tract, Metheuen \& Co Ltd, London.

9. Nizanski, W., Dubiel, A., Bielas, W. and Dejneka, G. J. 2001. J. Reprod. Fertil. (Suppl.) 57: 365-369.

10. Peña, A. I., Barrio, F., Quintela, L. A. and Herradon, P. G. 1998. Reprod. Dom. Anim. 33: 393-398.

11. Peña, A. and Linde-Forsberg, C. 2000. Theriogenology 54: 859-875.

12. Peña, A.I., Lopez-Lugilde, L., Barrio, M., Becerra, J.J., Quintela, L. A. and Herradon, P. G. 2003. Reprod. Dom. Anim. 38: 27-35.

13. Peña. A.I., Lugilde, L. L., Barrio, M., Herradon, P.G. and Quintela, L.A. 2003. Theriogenology 59: 1725-1739.

14. Pursel, V. G., Schulman, L. L. and Johnson, L. A. 1978. J. Anim. Sci. 47: 198-202.

15. Rota, A., Iguer-Ouada, M., Verstegen, J. and Linde-Forsberg, C. 1999. Theriogenology 51: 1045-1058.

16. Talbot, P. and Chacon, R. S. 1981. J. Exp. Zool. 215: 201-208.

17. Tsutsui, T., Hase, M., Hori, T., Ito, T. and Kawakami,E. 2000. J. Vet. Med. Sci. 62: 533-535.

18. Tsutsui, T., Hase, M., Hori, T., Komoriya, K., Shimizu, N., Nagakubo, K. and Kawakami, E. 2000. J. Vet. Med. Sci. 62: 537-538.

19. Tsutsui, T., Hase, M., Tanaka, A., Fujimura, N., Hori, T. and Kawakami, E. 2000. J. Vet. Med. Sci. 62: 603-606. 